\title{
Virtual Reality, help or hindrance? A case study of two undergraduate student- generated chemistry lessons
}

\author{
Stephen George-Williams ${ }^{\mathrm{a}}$, Reyne Pullen ${ }^{\mathrm{a}}$ and Siegbert Schmid ${ }^{\mathrm{a}}$ \\ Corresponding author: Stephen.George-Williams@sydney.edu.au \\ ${ }^{a}$ School of Chemistry, The University of Sydney, Sydney NSW 2006, Australia
}

Keywords: Virtual reality, undergraduate teaching, organic chemistry, audio recordings, concept inventories

\begin{abstract}
Virtual Reality (VR) has become a much more common household commodity thanks to the proliferation of more affordable VR devices. While its use in the gaming industry is becoming widespread, its application in pedagogical environments has only just started, particularly in chemistry. As such, whether VR will aid or hinder the teaching and learning of chemistry is currently a topic of research and debate. This project sought to generate VR materials designed to support students learning undergraduate chemistry, with the specific topics decided by undergraduate student researchers. This work was undertaken in the X-reality (i.e. VR and other forms of augmented realities) laboratories at the The University of Sydney. Preliminary materials were generated, and pilot tested with student volunteers who undertook pre- and post-questionnaires followed by an exit interview. The results of these trials showed that the VR experience did enhance student engagement and understanding, but only for more complex examples. The trial volunteers felt that ball-and-stick models were adequate for simple molecular representations. Nausea was noted as a significant issue alongside concerns around the inadequate response of the hand-held controls. This same issue made movement throughout the virtual environment difficult for several students. Lastly, the student researchers found generating the VR lessons to be challenging, noting a steep learning curve with regards to creating the environments.
\end{abstract}

\section{Introduction}

Over the past few decades, the use of a range of technological innovations has arisen both in modern teaching practices and in the education research literature. Some examples include remote laboratory experiences (Kennepohl, Baran, \& Currie, 2004), online simulations (Khan, 2013), animated 3D reaction processes (Rosenthal \& Sanger, 2013), in-class polling techniques (Pearson, 2019). In recent years, this has started to expand into the realms of Augmented Reality (AR) (Naese et al., 2019; Tee et al., 2018; Yang, Mei, \& Yue, 2018) and Virtual Reality (VR) (Ferrell et al., 2019; Probst \& Reymond, 2018) which allow for greater interactivity and, especially in the case of VR, immersion in an entirely different environment.

As dicussions around the use of AR and VR is relatively new in the literature, very little is known about the best ways to incorporate the experiences into everyday teaching practices. Focusing on VR, recent studies have shown that students are highly engaged in VR activities as they find the new environments, and increased interactivity, highly enjoyable (Ferrell et al., 2019). Further from this, Parong and Mayer (2018) showed that VR activities resulted in higher conceptual learning gains through post-quizzes. However, the students recalled less facts and basic information when compared to traditional means such as PowerPoint presentations. This same study also began to 
investigate the best use of the VR activities in student learning, showing that a segmented lesson (i.e. one in which students entered and exited the VR environment) was preferable to a continuous experience.

Akin to any use of technology, VR also has some notable issues. Firstly, the VR systems are known to cause nausea or feelings of motion sickness in some members of the population (Regan, 1995). Further from this, the controls can be challenging for some individuals to learn which may undermine the learning experience. It is difficult to know how many students may be affected by these issues while learning a given topic and is, therefore, an area of interest for future research. Additionally, as much of the literature in the VR space is relatively new, it is crucial to continue to produce new lesson examples for analysis to determine the best use of the platform.

In this pilot study, ten first-year undergraduate students were tasked with the generation of VR lessons that would be suitable for university students learning first-year chemistry. The students were given free rein of the topic area and chose to create two experiences to help teach VSEPR (Valence Shell Electron Pair Repulsion) theory and Stereoisomers. The lessons were designed for first-year students enrolled in undergraduate chemistry courses and were trialled with other undergraduate first-year students. Overall, this study sought to answer two main research questions:

1) What were the trial students' perceptions of the VR activity with regards to its physical use?

2) What effect did the VR activity have on the trial students' conceptual understanding of VSEPR and Stereoisomers?

\section{Methods}

\section{Theoretical frameworks}

Two theoretical frameworks underpinned both the lesson design and the research study.

Phenomenography is a theoretical approach to learning and research that focuses on the 'ways in which people experience, interpret, understand, perceive or conceptualise a certain phenomenon or aspect of reality' (Bodner \& Orgill, 2007, p. 128). In the case of this study, the lessons were designed to provide a new experience to students that would ideally help them learn two aspects of chemistry more readily, particularly with regards to being able to visualise abstract concepts. As such, the environments were created to be interactive and to allow for movement through the virtual world.

This framework also underpinned the research study through the use of semi-structured interviews As such, in line with the methodological guidelines stated by Bodner and Orgill (2007), the main form of data collection discussed in this paper will be the results of semi-structured interviews with trial students.

Symbolic interactionism is concerned with the construction of shared meanings (symbols) through social interaction and interpretation' (Bodner \& Orgill, 2007, p. 48). This could be interpreted as how students come to an understanding of the representations used in chemistry (e.g. molecular diagrams, reaction mechanisms or orbitals) through their interactions either with their peers, their 
educators or through the learning materials provided to them (Herman-Kinney \& Verschaeve, 2003). In this regard, VR allows students an opportunity to interact with chemistry symbols (molecular representations in this case) in a manner more aligned with the interpretation intended by their educators.

With regards to this research study, this framework guided the creation and analysis of the semistructured interviews and the pre- and post- quizzes and questionnaires. The questions were generally focused on the trial students' understanding of a range of chemical symbols and how the VR experiences may have altered them. It is important to note that these questions were not validated beyond the agreement of the authors.

\section{Lesson Development}

The lessons in this study were generated by a group of ten undergraduate students as a part of a first-year, second-semester research unit. These students were enrolled in a specialised course designed for high achieving students who showed great aptitude in their secondary subjects. The students were given the freedom to choose any topic that they believed that VR could help teach. As such, the two topic areas (VSEPR and Stereoisomers) were aligned with the students' perceptions, rather than the researchers.

The students used the NeosVR (2020) program to develop the lessons and were assisted by experts in the X-reality laboratory at The University of Sydney. Both lessons predominately involved the placement of example molecules with explanatory placards placed nearby (Figures 1 and 2). The molecules could be interacted with and in some cases, continually rotated in the VR environment. Participants were invited to walk between rooms and to discover the information at their own pace. The VSEPR lesson also included an interactive game in which students could place a variety of molecules into a container with their correct nomenclature (e.g. trigonal planar).

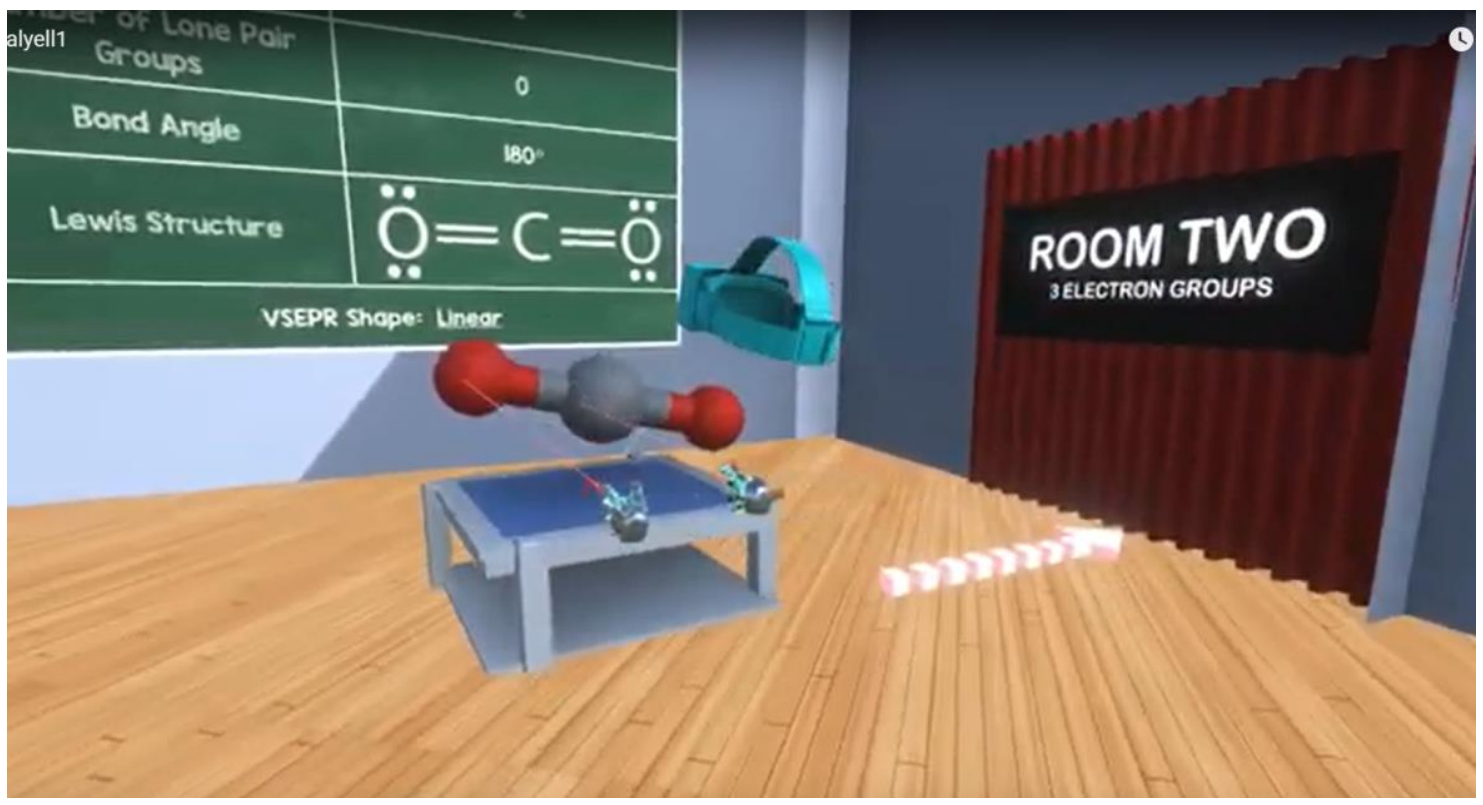

Figure 1: The VSEPR VR lesson with instructional materials on the wall and 'floating'/interactable molecules shown on tables 


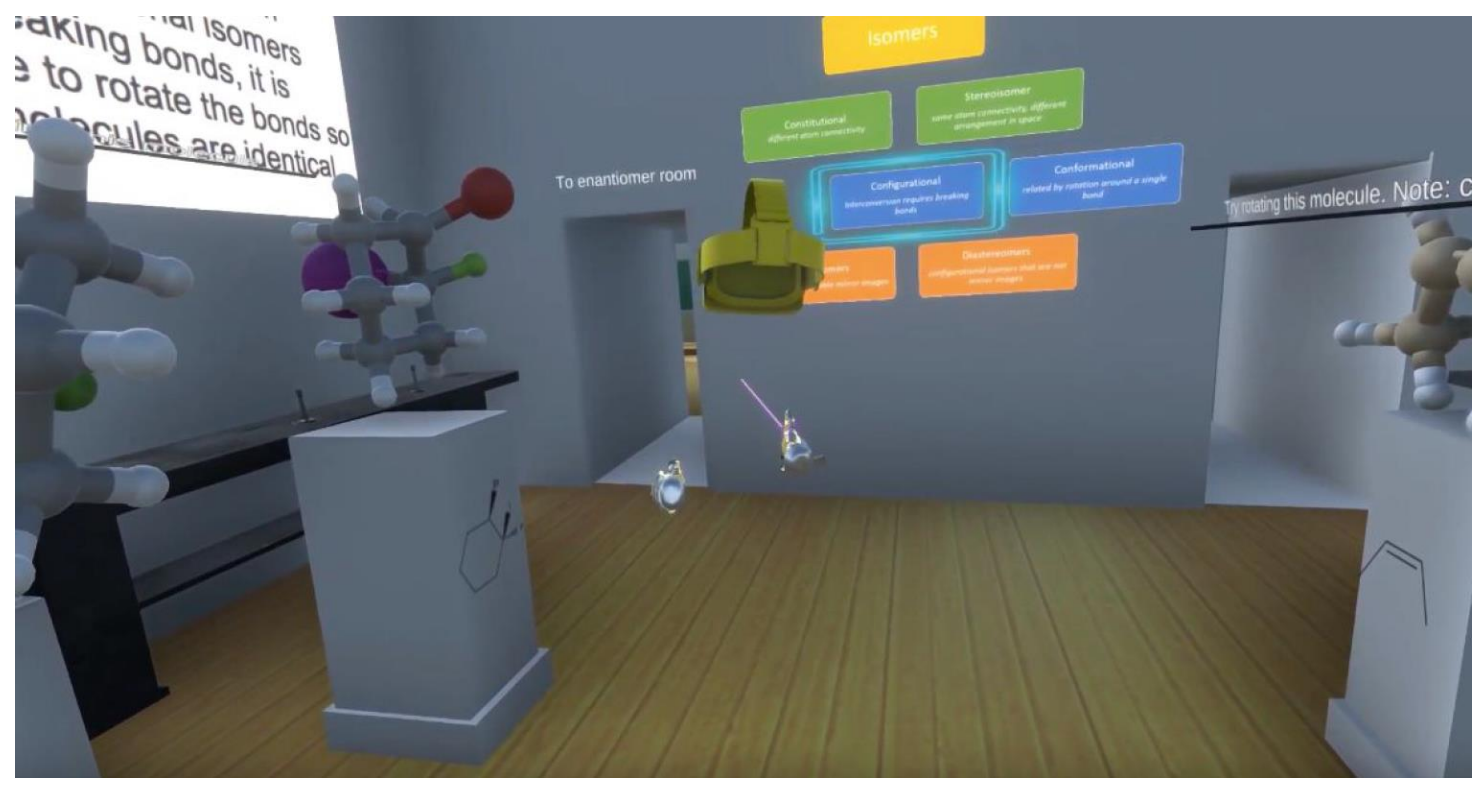

Figure 2: The Stereoisomer VR lesson with instructional materials on the wall and 'floating'/interactable molecules shown on pedestals.

\section{Student trials and data collection}

Once the lessons had been generated, first-year students were contacted via an announcement on the learning management system (Canvas in this case). The students were offered a $\$ 25$ gift card in exchange for participating in a trial activity involving the VR lessons. Eleven students volunteered to participate in the study. Of these students, some undertook multiple experiences on different days resulting in more trials than there were students. In the end, three control group trials (i.e. learning materials with no VR component) and four VR trials were run for both topic areas.

The trials were run with conditions as similar as possible. The trial students completed a prequestionnaire (Appendix 1) and a pre-quiz in their respective topic area. Following this, students were given access to two pages of online material explaining their topic area. This information was sourced from the first-semester chemistry courses already undertaken by all participants. Next, the students took either the control experience (predominately paper-based questions and ball-andstick models) or the VR lessons. The trials were then completed with a post-questionnaire (Appendix 2), a post-quiz and then an exit interview with one of the three authors (Appendix 3).

\section{Data analysis}

Due to the small sample size, no statistical analysis was performed on the students' pre-post quiz results. The presence of trends in the results, however, was still investigated. For the interview data, a thematic analysis protocol was utilised. Here, the three researchers all read the interview transcripts independently and noted any themes that emerged. After this, the three sets of themes were compared, and any changes required were the result of modifications agreed upon by all three researchers. 


\section{Limitations}

One limitation of this study was the sample size. With only eight participants experiencing the VR tutorials and six undertaking the traditional lessons, it is impossible to perform any meaningful statistical analysis. However, these results should be considered preliminary and only provide insight into potential benefits and pitfalls when designing VR activities. Additionally, the small sample size meant that the number of interviews was fixed, rather than new interviews being undertaken until saturation was noted.

The next major limitation was the number of concepts being studied, which was only two in this case. Again, the preliminary nature of this investigation limits the scope of the topic areas that could be reasonably covered.

Lastly, the student participants had already encountered the topics in their previous studies. As such, these results cannot be used to determine if students learning the topic areas for the first time would find the VR lessons more or less impactful, or in what ways.

\section{Results and Discussion}

\section{Questionnaire and theoretical quiz}

Each student was asked eight theory-based questions relating to either VSEPR or Stereoisomers both before and after their exercise. These quizzes aimed to measure the students conceptual understanding of either VSEPR or Stereoisomers. The average differences between the pre- and post-test scores were used to indicate the effect of either the control or VR lessons (Table 1).

Table 1: The average marks (/8) for students participating in the control groups $(\mathrm{N}=3)$ or the VR groups $(\mathrm{N}=4)$

\begin{tabular}{|l|c|c|c|c|c|c|}
\cline { 2 - 7 } \multicolumn{1}{c|}{} & \multicolumn{3}{c|}{ VSEPR } & \multicolumn{3}{c|}{ Stereoisomers } \\
\cline { 2 - 7 } & $\begin{array}{c}\text { Average Pre- } \\
\text { mark (/8) }\end{array}$ & $\begin{array}{c}\text { Average } \\
\text { Post-mark } \\
(/ 8)\end{array}$ & $\begin{array}{c}\text { Difference } \\
\text { between Pre } \\
\text { and Post }\end{array}$ & $\begin{array}{c}\text { Average } \\
\text { Pre-mark } \\
(/ 8)\end{array}$ & $\begin{array}{c}\text { Average } \\
\text { Post-mark } \\
(/ 8)\end{array}$ & $\begin{array}{c}\text { Difference } \\
\text { between Pre } \\
\text { and Post }\end{array}$ \\
\hline Control group & 5.67 & 6.00 & 0.33 & 4.33 & 3.67 & -0.67 \\
\hline VR Group & 6.25 & 6.25 & 0.00 & 2.00 & 3.50 & 1.50 \\
\hline
\end{tabular}

The data indicate that the VSEPR VR experience had no measurable effect on the students' conceptual understanding, whereas the control experience had a slightly positive influence (increase by 0.33 ). Interestingly, the Stereoisomers VR experience showed a much larger positive effect (average of 1.5), whereas the control experience, in this case, had a negative impact (-0.67). With so few students participating in this study, it is unwise to overgeneralise these findings. Still, at the very least these results would appear to indicate that the utilisation of VR may not be equally impactful across all areas of chemistry (or indeed throughout the other sciences).

The students were also asked to consider nine closed questions concerning the exercises that they undertook. Three of these questions, relating to their general confidence in chemistry and their self-perceived ability to visualise/mentally rotate molecules were asked both before and after the 
experience. The average differences in their responses to the items asked through a typical Likert survey were used to highlight the most relevant changes but were not used for any statistical testing. These results are shown in Table 2.

Table 2: The average response to three pre- and post-closed questions which utilised Likert scales (1=Strongly Disagree, 2=Disagree, 3=Neutral, 4=Agree and 5=Strongly Agree) for the control groups $(\mathrm{N}=3)$ and VR groups $(\mathrm{N}=4)$

\begin{tabular}{|c|c|c|c|c|c|c|c|}
\hline & \multicolumn{3}{|c|}{ VSEPR } & \multicolumn{3}{|c|}{ Stereoisomers } \\
\hline & & $\begin{array}{l}\text { Average } \\
\text { Pre- } \\
\text { response }\end{array}$ & \begin{tabular}{|l|} 
Average \\
Post- \\
response \\
\end{tabular} & $\begin{array}{l}\text { Difference } \\
\text { between Pre } \\
\text { and Post }\end{array}$ & $\begin{array}{l}\text { Average } \\
\text { Pre- } \\
\text { response }\end{array}$ & $\begin{array}{l}\text { Average } \\
\text { Pre- } \\
\text { response }\end{array}$ & $\begin{array}{l}\text { Difference } \\
\text { between Pre } \\
\text { and Post }\end{array}$ \\
\hline \multirow{2}{*}{$\begin{array}{l}\text { Confidence in } \\
\text { chemistry }\end{array}$} & $\begin{array}{l}\text { Control } \\
\text { group }\end{array}$ & 3.00 & 3.33 & 0.33 & 3.00 & 3.67 & 0.67 \\
\hline & $\begin{array}{l}\text { VR } \\
\text { Group }\end{array}$ & 3.75 & 4.25 & 0.50 & 3.00 & 3.25 & 0.25 \\
\hline \multirow{2}{*}{$\begin{array}{l}\text { Ability to } \\
\text { visualize in } \\
\text { 3D space }\end{array}$} & $\begin{array}{l}\text { Control } \\
\text { Group }\end{array}$ & 3.00 & 3.00 & 0.00 & 2.67 & 1.67 & -1.00 \\
\hline & $\begin{array}{l}\text { VR } \\
\text { Group }\end{array}$ & 4.00 & 3.33 & -0.67 & 2.33 & 4.00 & 1.67 \\
\hline \multirow{2}{*}{$\begin{array}{l}\text { Ability to } \\
\text { mentally } \\
\text { rotate } \\
\text { molecules in } \\
\text { 3D space }\end{array}$} & $\begin{array}{l}\text { Control } \\
\text { Group }\end{array}$ & 2.33 & 3.33 & 1.00 & 2.67 & 1.67 & -1.00 \\
\hline & $\begin{array}{l}\text { VR } \\
\text { Group }\end{array}$ & 3.75 & 3.00 & -0.75 & 3.00 & 4.00 & 1.00 \\
\hline
\end{tabular}

In general, the VSEPR VR lessons appeared less impactful (and perhaps even negatively so) when compared to both the control experiences and the Stereoisomers VR lessons. It is important to note however that the pre-scores differed between the two groups implying a non-random representation of students resulting from the small sample size. These results indicated that students undertaking the Stereoisomers VR lessons were more likely to feel that they could visualise and rotate molecules in their minds. In contrast, students who took the VSEPR lessons felt less able to do so but as this is the students' perception of themselves, this may not actually be true. Again, this is difficult to generalise, but it appears to corroborate the perception that not all chemistry/science topics can be successfully taught using VR. More in-depth interview data are required to understand these findings further, and these are covered later in this article.

The remaining six closed questions were only asked after students had completed their lessons and asked the students to consider the effect of their experience on a) their theoretical understanding, b) how helpful the provided equipment/materials were, c) how necessary the provided equipment/materials were, d) how engaging the lessons were, e) how much the lessons helped them focus and $\mathrm{f}$ ) whether they would like to encounter the provided equipment/materials in the future. The average responses to these questions are shown in Table 3. 
Table 3: The average response to six post-closed questions which utilized Likert scales (1=Strongly Disagree, 2=Disagree, 3=Neutral, 4=Agree and 5=Strongly Agree) for the control groups $(\mathrm{N}=3)$ and VR groups $(\mathrm{N}=4)$

\begin{tabular}{|l|l|c|c|c|c|c|c|}
\cline { 2 - 8 } \multicolumn{2}{|c}{} & $\begin{array}{c}\text { Theoretical } \\
\text { understanding }\end{array}$ & Helpfulness & Necessity & Engagement & $\begin{array}{c}\text { Effect on } \\
\text { focus }\end{array}$ & $\begin{array}{c}\text { Desire } \\
\text { for future } \\
\text { use }\end{array}$ \\
\hline \multirow{3}{*}{ VSEPR } & Control result & 4.00 & 3.33 & 3.67 & 3.33 & 4.00 & 3.33 \\
\cline { 2 - 9 } & VR result & 4.25 & 4.25 & 3.00 & 4.75 & 4.25 & 4.75 \\
\cline { 2 - 9 } & Difference & 0.25 & 0.92 & -0.67 & 1.42 & 0.25 & 1.42 \\
\hline \multirow{3}{*}{ Stereoisomers } & Control result & 4.67 & 3.67 & 4.00 & 4.33 & 3.67 & 4.33 \\
\cline { 2 - 9 } & VR result & 3.50 & 3.75 & 3.00 & 3.50 & 4.50 & 3.25 \\
\cline { 2 - 9 } & Difference & -1.17 & 0.08 & -1.00 & -0.83 & 0.83 & -1.08 \\
\hline
\end{tabular}

The results shown in Table 3 indicate that the students were generally more positive about the VSEPR VR experience, both when compared to the control group responses and to the Stereoisomers group responses. This difference in perception is particularly of note as it was the students who undertook the Stereoisomers VR experience who performed better on their theoretical quiz. Furthermore, both groups of VR students were less likely to state that the equipment or materials provided were 'necessary' to their understanding after completing the online modules.

Overall, the results of both the quizzes and closed questions suggest that the VR lessons were not particularly impactful in this case. To better understand why this may be, as several literature studies indicate that the VR lessons should have been successful (Bennie et al., 2019; Ferrell et al., 2019; Jiménez, 2019), the data resulting from the exit-interviews must be considered.

\section{Trial student exit interviews}

Two theoretical frameworks (Phenomenography and Symbolic Interactionism) were used as lenses to analyse the student interviews and to separate student comments into two main categories.

\section{Phenomenography}

Through this lens, all student comments about the physical nature of using and experiencing the VR environment were placed together. From here, the themes most commonly raised by the students, and some exemplar quotes, are shown in Table 4. 
Table 4: The main themes noted in the student interviews when considering the physical aspects of using the VR system

\begin{tabular}{|c|c|}
\hline $\begin{array}{c}\text { Theme } \\
\text { (number of students who raised the theme) }\end{array}$ & Representative quote(s) \\
\hline $\begin{array}{l}\text { Using the controls to move through the VR } \\
\text { environment and interact with the molecules } \\
\text { was either easy to do/learn ( } 3 \text { ) or was very } \\
\text { difficult/required further training (5). }\end{array}$ & $\begin{array}{l}\text { 'Oh, yeah, like it [the controls] takes like two } \\
\text { minutes to get used to' } \\
\text { OR } \\
\text { 'I found the control is quite difficult, quite } \\
\text { confusing, and sometimes it don't want you to } \\
\text { go forward.' }\end{array}$ \\
\hline $\begin{array}{l}\text { The VR environment was engaging, visually } \\
\text { appealing or fun (4) }\end{array}$ & $\begin{array}{l}\text { 'I found with the VR like you can learn from } \\
\text { it. But I feel like I was having more fun.' }\end{array}$ \\
\hline $\begin{array}{l}\text { The VR environment caused a feeling of } \\
\text { nausea (5) }\end{array}$ & $\begin{array}{l}\text { 'It does kind of give you a bit of a headache } \\
\text { after a while, and it makes you feel sick and } \\
\text { like woozy.' }\end{array}$ \\
\hline $\begin{array}{l}\text { The VR environment did not cause feelings of } \\
\text { nausea (4) }\end{array}$ & $\begin{array}{l}\text { 'I have a pretty good feeling using this. I don't } \\
\text { feel nausea.' }\end{array}$ \\
\hline
\end{tabular}

The interview analysis shows that while several students found the environment to be engaging or 'fun' (4), many of the students either felt nauseous (5) or struggled to utilise the controllers (5) adequately. Furthermore, some subthemes emerged with a couple of students desiring an even more interactive environment or struggled due to their need to wear glasses. Lastly, two individual students found the environment uninteresting or overwhelming. Perhaps avoiding the use of traditional classroom environments in favour of more 'interesting' environments (e.g. a futuristic or fantastical environment) may help increase student buy-in. These physical concerns will need to be addressed before the VR lessons could be utilised on a larger scale. Current understanding of VR would suggest that limiting movement would help with nausea as this is likely the result of 'motion sickness' (Kim, Park, Choi, \& Choe, 2018). Alongside this, asking the students to only interact with the VR environment for short periods of time may also help with these issues. Lastly, only VR models/head sets that allow for learners to continue the use of any required prescription glasses should be utilised.

\section{Symbolic interactionism}

Through this lens, all student comments about the lesson design and its effect on conceptual understanding were placed together. From here, the themes most commonly raised by the students, and some exemplar quotes, are shown in Table 5. 
Table 5: The main themes noted in the student interviews when considering the effect of using the VR system on theoretical learning/interactions with molecular representations and symbols

\begin{tabular}{|c|c|}
\hline $\begin{array}{c}\text { Theme } \\
\text { (number of students who raised the theme) }\end{array}$ & Representative quote(s) \\
\hline $\begin{array}{l}\text { The VR environment allowed for a more } \\
\text { straightforward, accurate mental conversion } \\
\text { of } 2 \mathrm{D} \text { objects into 3D. (7) }\end{array}$ & $\begin{array}{l}\text { 'Even though it's a 3D representation of the } \\
\text { molecule [referring to in-lecture examples], } \\
\text { but we are limited by personal imagination as } \\
\text { to how the molecules would look like and } \\
\text { using this technology definitely boosts our } \\
\text { understanding how the molecules actually look } \\
\text { like and the visual representation.' }\end{array}$ \\
\hline $\begin{array}{l}\text { The VR lessons would work better in } \\
\text { combination with other learning media/modes } \\
\text { (6) }\end{array}$ & $\begin{array}{l}\text { 'I found was like with the video. I learned how } \\
\text { to like actually draw the structures, whereas } \\
\text { with the VR over more sort of learned like how } \\
\text { they fit into space. So I feel that they more } \\
\text { complemented each other rather than being } \\
\text { better like stand alone.' }\end{array}$ \\
\hline $\begin{array}{l}\text { The VR lessons would be better suited to } \\
\text { more complex examples (such as reaction } \\
\text { mechanisms) (3) }\end{array}$ & $\begin{array}{l}\text { 'I could possibly see potential for some sort of } \\
\text { VR learning for the different reaction } \\
\text { mechanisms' }\end{array}$ \\
\hline
\end{tabular}

Many students (7) noted that the VR environment did allow for a much easier conversion between 2D and 3D imagery. It is worth noting that students often referred to the molecules as 'real' representations rather than theoretical representations, which may create misconceptions in their later learnng. Beyond this, one student stated that they finally understood the reasoning for specific nomenclature (e.g. the T-shape in VSEPR). Another student also appreciated that VR could allow for much easier comparison between a larger number of molecules (as no physical models were required to be built). These findings agree with other literature sources about the potential for VR to expand visual understanding beyond just rote memorisation of images and nomenclature (Parong \& Mayer, 2018; Won, Mocerino, Tang, Treagust, \& Tasker, 2019).

The next major theme showed that despite nausea and the problematic control use mentioned earlier on, most students felt that the VR system would be a great addition to other learning modes (6). This finding aligns well with the aforementioned plans to segment the VR lessons with paperbased tutorials (or similar) to avoid nausea. Indeed, this has been shown in the previously raised work of Parong and Mayer (2018) to lead to better learning outcomes for students when learners entered and exited the VR environment more frequently. Further from this, several students (3) felt that the VR lessons could be particularly useful for more complex examples, such as organic reaction mechanisms, which is a potentially promising area of future research. It should be noted, however, that the reason that organic reactions, in particular, were mentioned, is likely due to the topics being covered in the chemistry courses at the times of the tutorials - which was organic reaction mechanisms. 
While only raised by a few students, several smaller individual themes were noted indicating that a) two students desired an increase in either peer-peer or peer-teacher interaction, b) two students felt that the lessons did not affect their learning and c) one thought that the environment might be too distracting or overwhelming. It is worth noting that the VR environment is unlike any other environment that most students have encountered in their daily lives. As such, the sheer novelty of the new learning space likely results in an increased cognitive load when being utilised, which could account for the comments about limited learning gains or the overwhelming nature of the environment. This issue of potential cognitive overload is akin to the work of Kirschner, Sweller, Kirschner, and Zambrano (2018) that showed that any group work undertaken was only useful if an individual could not easily complete the task alone. As such, when and where the VR equipment is used needs to be carefully considered to maximise its novelty and engagement factor, as overuse of the device would likely lead to fatigue and potentially lower learning outcomes when compared to more appropriate learning modes.

\section{Conclusions}

This study sought to measure the effect of VR on student learning, specifically with relation to two student chosen chemistry concepts - VSEPR and Stereoisomers. Eleven student volunteers participated in either control experiences or VR experiences, and these trials formed the basis of this study. Through the use of pre- and post-quizzes and questionnaires, the results appeared to show that there was an inconsistent effect on student understanding, with only the Stereoisomers lesson resulting in a higher learning gain when compared to more traditional teaching methods. In contrast to this, student responses showed that they felt more positively towards the VSEPR lesson and that they gained more from this experience. Clearly, VR may not be equally impactful or as well-received for all topic areas.

Student interviews provided a more in-depth view of the students' experiences, with thematic analysis providing the most common themes raised. In general, the students were positive about the VR experience, stating that the VR environments were fun/engaging and allowed for easier visualisation of $3 \mathrm{D}$ structures. It was common for students to report that the VR environments would work well in conjunction with other learning modes and some students also raised the potential for VR with relation to more complex examples and molecules.

Student issues with the VR environment mostly centred around the potential to feel nausea and the difficulty of using the VR controls to move around and interact with the VR space. However, this was not consistent across all student participants, indicating that perhaps with training and more time in the VR environment, these issues may decrease. Further from this, future lessons could be created with fewer movement requirements and be designed to allow students to continually enter and exit the VR space, thereby potentially limiting nausea.

Overall, essential considerations for VR design were evidenced throughout this article. There is a large amount of future work to be done, namely expanding the topics to other more complex examples in chemistry (organic reaction mechanisms, surface interactions, solvation effects etc.) and alterations to future lesson design to avoid the most common pitfalls of nausea and control use. The particular VR lessons generated in this study may not be suitable for direct classroom 
use, but their generation and subsequent student trials can help pave the way to more impactful lessons in the future.

\section{Acknowledgements}

We acknowledge and pay respect to the Gadigal people of the Eora Nation, the traditional owners of the land on which we research, teach and collaborate at the University of Sydney.

The authors would like to acknowledge the student designers (Srikar Ayalasomayajula, Louise Cai, Harrison Chong, Zahraa Khan, Devika Koroth, Dev Lalwani, Sunny Lee, Amy Teo, Shalini Vijeyakumar and Kevin Wu) alongside their senior student mentor (Jia Xin Quek). While the design of the VR lessons was part of a credit-bearing course, these students did a fantastic job above and beyond expectations while generating the lessons and facilitating the trials.

Next, the authors would like to acknowledge the team members in the X-reality laboratories (Dr Elodie Chiarovano, A/Prof. Hamish MacDougal and Prof. Frans Verstraten). Their guidance and support, particularly in the use of the NeosVR project, was much appreciated. Additonally, the help and guidance of Professor Philip Poronnik, who spent time showing the students other potential platforms for the VR lessons, was greatly appreciated.

Lastly, as with all such educational research, we would like to thank the student volunteers. Their time and insight will hopefully lead to better and more impactful VR lessons in the future.

\section{References}

Bennie, S. J., Ranaghan, K. E., Deeks, H., Goldsmith, H. E., O’Connor, M. B., Mulholland, A. J., \& Glowacki, D. R. (2019). Teaching Enzyme Catalysis Using Interactive Molecular Dynamics in Virtual Reality. Journal of Chemical Education, 96(11), 2488-2496. doi:10.1021/acs.jchemed.9b00181

Bodner, G. M., \& Orgill, M. (2007). Theoretical frameworks for research in chemistry/science education.

Ferrell, J. B., Campbell, J. P., McCarthy, D. R., McKay, K. T., Hensinger, M., Srinivasan, R., Zhao, X.

Wurthmann, A. Li, J. \& Schneebeli, S. T. (2019). Chemical Exploration with Virtual Reality in Organic Teaching Laboratories. Journal of Chemical Education, 96(9), 1961-1966. doi:10.1021/acs.jchemed.9b00036

Herman-Kinney, N. J., \& Verschaeve, J. M. (2003). Methods of Symbolic Interactionism.

Jiménez, Z. A. (2019). Teaching and Learning Chemistry via Augmented and Immersive Virtual Reality. In Technology Integration in Chemistry Education and Research (TICER) (Vol. 1318, pp. 31-52): American Chemical Society.

Kennepohl, D., Baran, J., \& Currie, R. (2004). Remote Instrumentation for the Teaching Laboratory. Journal of Chemical Education, 81(12), 1814. doi:10.1021/ed081p1814

Khan, S. (2013). The Future of Computer Simulations Designed for Classroom Instruction. In Pedagogic Roles of Animations and Simulations in Chemistry Courses (Vol. 1142, pp. 341-365): American Chemical Society.

Kim, H. K., Park, J., Choi, Y., \& Choe, M. (2018). Virtual reality sickness questionnaire (VRSQ): Motion sickness measurement index in a virtual reality environment. Applied ergonomics, 69, 66-73.

Kirschner, P. A., Sweller, J., Kirschner, F., \& Zambrano, J. (2018). From cognitive load theory to collaborative cognitive load theory. International Journal of Computer-Supported Collaborative Learning, 13(2), $213-233$.

Naese, J. A., McAteer, D., Hughes, K. D., Kelbon, C., Mugweru, A., \& Grinias, J. P. (2019). Use of Augmented Reality in the Instruction of Analytical Instrumentation Design. Journal of Chemical Education, 96(3), 593-596. doi:10.1021/acs.jchemed.8b00794

NeosVR. (2020). NEOS. Retrieved from https://neosvr.com/

Parong, J., \& Mayer, R. E. (2018). Learning science in immersive virtual reality. Journal of Educational Psychology, 110(6), 785. 
Pearson, R. J. (2019). Exploring Peer Instruction: Should Cohort Clicker Responses Appear During or After Polling? Journal of Chemical Education, 96(5), 873-879. doi:10.1021/acs.jchemed.9b00035

Probst, D., \& Reymond, J.-L. (2018). Exploring DrugBank in Virtual Reality Chemical Space. Journal of Chemical Information and Modeling, 58(9), 1731-1735. doi:10.1021/acs.jcim.8b00402

Regan, C. (1995). An investigation into nausea and other side-effects of head-coupled immersive virtual reality. Virtual Reality, 1(1), 17-31.

Rosenthal, D. P., \& Sanger, M. J. (2013). How does viewing one computer animation affect students' interpretations of another animation depicting the same oxidation-reduction reaction? Chemistry Education Research and Practice, 14(3), 286-296. doi:10.1039/C3RP00006K

Tee, N. Y. K., Gan, H. S., Li, J., Cheong, B. H.-P., Tan, H. Y., Liew, O. W., \& Ng, T. W. (2018). Developing and Demonstrating an Augmented Reality Colorimetric Titration Tool. Journal of Chemical Education, 95(3), 393399. doi:10.1021/acs.jchemed.7b00618

Won, M., Mocerino, M., Tang, K.-S., Treagust, D. F., \& Tasker, R. (2019). Interactive Immersive Virtual Reality to Enhance Students' Visualisation of Complex Molecules. In Research and Practice in Chemistry Education (pp. 51-64): Springer.

Yang, S., Mei, B., \& Yue, X. (2018). Mobile Augmented Reality Assisted Chemical Education: Insights from Elements 4D. Journal of Chemical Education, 95(6), 1060-1062. doi:10.1021/acs.jchemed.8b00017 